\title{
Dissertação nos manuais escolares do ensino médio: entre mudanças e permanências
}

\author{
Maria Inês Batista Campos $^{l}$
}

\begin{abstract}
In this article, the objective is to discuss the teaching of the dissertation in two textbooks of high school published between 1980 and 2000 , systematically studied, to characterize the transformations occurred in the teaching of dissertation/argumentation, as part of a public policy established at the beginning of the military dictatorship. In the first part of the article, some official documents that marked the teaching of written production, particularly the dissertation, will be considered by pointing out aspects that defined this school genre in a monological way. In the second part, we analyze the didactic sequences formulated in didactic manuals and, in the final considerations, we compare how the teaching model in the interval of two decades oscillates between dissertation and argumentation, without the concern of placing the argumentative questions in a dialogical way. The way to teach the production of essay-argumentative texts in school textbooks remains in the textbooks as a school year in which students must develop an idea, following the formal structure of introduction, development and completion. Disserting how to argue, how to confront different points of view, respecting the opinion of the other, facing diversity is not a proposal of the didactic activities present in the manuals until the beginning of the 21 st century.
\end{abstract}

Keywords: Dissertation; argumentation; textbooks; writing; point of view.

Resumo: Neste artigo, o objetivo é discutir o ensino da dissertação em dois manuais didáticos do ensino médio publicados entre 1980 e 2000, estudados sistematicamente, a título de caracterizar as transformações ocorridas no ensino de dissertação / argumentação, como parte de uma política pública instaurada no início da ditadura militar. Na primeira parte do artigo, serão retomados alguns documentos oficiais que marcaram o ensino da produção escrita, particularmente, a dissertação, apontando aspectos que definiram esse gênero escolar de forma monológica. Na segunda parte, analisamos as sequências didáticas formuladas nos manuais didáticos e, nas considerações finais, comparamos como o modelo de ensino no intervalo de de duas décadas oscila entre dissertação e argumentação, sem a preocupação de colocar as questões argumentativas de forma dialógica. $\mathrm{O}$ modo de ensinar a produzir textos dissertativo-argumentativos nos manuais escolares mantém-se nos livros didáticos como exercício escolar em que os alunos devem desenvolver uma ideia, seguindo a estrutura formal de introdução, desenvolvimento e conclusão. Dissertar como argumentar, como confrontar pontos de vista diferentes, respeitando a opinião do outro,

1 Professora, pesquisadora e orientadora do Programa de Pós-Graduação em Filologia e Língua Portuguesa e do Mestrado Profissional em Letras (Profletras) do Departamento de Letras Clássicas e Vernáculas da Faculdade de Filosofia, Letras e Ciências Humanas da Universidade de São Paulo. Integrante dos Grupos de Pesquisa GEDUSP (Grupo de estudos do discurso da USP) e Linguagem, Identidade e Memória (CNPq/PUC-SP). 
enfrentando a diversidade não é proposta das atividades didáticas presentes nos manuais até o início do século XXI.

Palavras-chave: Dissertar; argumentar; manuais didáticos; redação; ponto de vista.

\section{Introdução}

Inicio o presente artigo com um trecho do ensaio $\mathrm{O}$ discurso na poesia e o discurso no romance, em que Mikhail Bakhtin expõe a presença do diálogo em todos os discursos ("do dia a dia, o retórico, o científico"), desenvolvida por um sujeito a seu interlocutor. A concepção de argumentação adotada nesta análise tem como fundamentação teórica a teoria dialógica do discurso:

[...] o discurso surge no diálogo como sua réplica viva, forma-se na interação dinâmica com o discurso do outro no objeto. A concepção do seu objeto pelo discurso é dialógica. [...] Nas formas retóricas, [...] consideravam apenas os aspectos do estilo que são determinados pelas exigências de inteligibilidade e clareza, isto é, justamente aqueles aspectos desprovidos de dialogicidade interna, que só consideram o ouvinte como alguém que compreende passivamente, mas não responde e objeta ativamente (BAKHTIN, 2015, p. 52-53).

Alguns conceitos como interação, diálogo, interlocutores são elementos constitutivos da escrita argumentativa, em que há um conjunto de argumentos e contra-argumentos relacionados a uma situação concreta. $\mathrm{O}$ efeito dessa perspectiva teórica na compreensão do discurso argumentativo é significativo, por abrir para o entendimento do discurso como uma réplica ativa e responsiva, em que o os indivíduos têm o que o dizer, para quem dizer, em situação real, em tempo real.

$\mathrm{O}$ ensino da dissertação, no entanto, desde as últimas décadas do século $\mathrm{XX}$, mantiveram-se ligados, quase que exclusivamente a aspectos composicionais e não aos discursivos. Nos manuais didáticos de português dirigidos ao ensino médio, a dissertação aparece pouco conectada aos modos linguísticos de organização argumentativo. Para melhor compreender como a dissertação entrou nos manuais escolares produzidos no Brasil, é preciso recuperar as condições históricas a partir década de 1970, momento em que esse tipo de texto passou a ser ensinado de modo sistemático.

O objetivo deste artigo é recuperar o ensino da dissertação em dois manuais didáticos do ensino médio publicados entre 1980 e 2000, estudados sistematicamente, a título de caracterizar as transformações ocorridas no ensino desse tipo de redação, como parte de uma política pública instaurada no início da ditadura militar. Na primeira parte do artigo, serão retomados alguns documentos oficiais que marcaram o ensino da produção escrita, particularmente, a dissertação, apontando aspectos que definiram esse gênero escolar de forma monológica. Na segunda parte, analisamos as sequências didáticas formuladas nos manuais didáticos e, nas considerações finais, comparamos como o modelo de ensino no intervalo de duas décadas oscila entre dissertação e argumentação, sem preocupação de colocar as questões argumentativas de forma dialógica. O modo de ensinar a produzir textos dissertativo-argumentativos nos manuais escolares mantém-se nos livros didáticos como exercício escolar em que os alunos são convocados a desenvolver uma ideia, seguindo a estrutura composicional de introdução, desenvolvimento e conclusão. Dissertar como argumentar, como confrontar pontos de vista diferentes, respeitando a opinião do outro, enfrentando a diversidade não é foco das atividades didáticas presentes nos manuais até o início do século XXI. 
No início dos anos 1960, a disciplina de português alterou-se substancialmente com a promulgação da Lei de Diretrizes e Bases (LDB) 4.024 de 1961 no governo do presidente João Goulart. O curso secundário foi dividido em dois ciclos: ginasial (4 anos) e colegial (3 anos), momento em que as condições culturais e linguísticas foram modificadas, trazendo nova concepção de linguagem. Alguns fatores levantados por Soares (2004, p. 167) sinalizam as alterações: a) democratização da escola com a duplicação de alunos das camadas populares no ensino primário e a triplicação no ensino médio; b) O conteúdo ensinado tem foco na gramática articulada ao texto.

Manteve-se, no entanto, uma valorização da gramática, centralizada nos estudos descritivos da norma gramatical, em que se manteve um ensino homogêneo e abstrato e um desprezo pela heterogeneidade de discursos e falares. A "redação escolar" foi introduzida nesse período, com textos para leitura que serviam de estímulo para a escrita. Bunzen ressalta que naquele período "continuamos não encontrando um espaço dedicado ao ensino de produção escrita, pois o texto "era tomado como objeto de uso, mas não de ensino-aprendizagem." (2006, p. 144).

Foi mesmo na década de 1970 que as aulas de redação se tornaram muito valorizadas devido à implantação da Lei de Diretrizes e Bases da Educação (LDB), n. 5692/1971. Elaborada na gestão do presidente Emílio Garrastazu Médici (1969-1974), o conteúdo fez parte do projeto socioeconômico e político-cultural da ditadura militar brasileira (1964-1985). Houve uma radical transformação social e cultural no país, ocorrendo uma reformulação também no ensino primário e médio:

No ensino de $1^{\circ}$ e $2^{\circ}$ graus, dar-se-á especial relevo ao estudo da língua nacional, como instrumento de comunicação e como expressão da cultura brasileira. (Lei 5692/71, Art.1 ${ }^{\circ}$, parágr. Único.)

A disciplina passou a ser designada de "Comunicação e expressão" nas séries iniciais do $1^{\circ}$ Grau e "Comunicação em língua portuguesa" de $5^{\mathrm{a}}$ à $8^{\mathrm{a}}$ séries (atualmente Ensino Fundamental anos finais); no $2^{\circ}$ grau recebeu o nome de "Língua portuguesa e literatura brasileira" (atualmente Ensino médio). A ação instaurada pelo governo militar, no período pós-1964, ampliou a rede pública, alinhando a escola ao mercado de trabalho, criado, na época do que se chamou o "milagre brasileiro". Frente a nova realidade linguística dos alunos, o ensino passou a ter como base a Teoria da Comunicação e a língua entendida como instrumento de comunicação. As bases educacionais estavam ancoradas no Pragmatismo de Dewey e na Psicologia de Piaget.

Várias modificações estruturais foram instituídas, entre elas a elaboração dos conteúdos curriculares fundada em torno de uma visão tecnicista e os objetivos passaram a ser pragmáticos e utilitários. A prioridade foi dada ao estudo da língua nacional, "como instrumento de comunicação e como expressão da cultura brasileira" (BRASIL, 1971); e textos como propagandas, histórias em quadrinhos, fotografias, isto é, diferentes códigos foram incorporados ao lado dos textos literários.

No final dessa década, a prova de redação nos exames vestibulares tornou-se obrigatória com o Decreto Federal n. 79.298, de 24 de fevereiro de 1977. Bunzen explica que "As escolas começaram a dar mais ênfase ao ensino de redação [...] e introduziram uma "nova disciplina" grade curricular no $2^{\circ}$ Grau com o objetivo de ensinar os alunos a 
fazer redações, digo dissertações" (2006, p. 146). Com essa nova orientação, a produção de livros didáticos cresceu consideravelmente, particularmente, dirigida ao ensino de redação ${ }^{2}$ no $2^{\circ}$ grau. Soares; Nascimento explicam o sentido de dissertação aos professores e alunos no prefácio de Técnica de redação: as articulações linguísticas como técnica de pensamento, obra publicada em 1978 que teve várias edições:

A DISSERTAÇÃO é a forma de REDAÇÃO mais usual. [...] A prosa dissertativa é, assim, predominante nos textos de trabalhos escolares, nos textos de produção e divulgação científicas (monografias, ensaios, artigos e relatórios técnico-científicos) e nos textos técnicos-administrativos. Raramente é uma pessoa solicitada a produzir uma descrição ou uma narração; frequentemente, ao contrário, é solicitada a produzir uma dissertação (SOARES; NASCIMENTO, 1978, p. v).

O conceito de língua nas aulas de português passou a ser considerado como instrumento para o desenvolvimento e, por isso, a serviço da ideologia política do novo regime. Segundo Soares: “[...] os objetivos passam a ser pragmáticos e utilitários: trata-se de desenvolver e aperfeiçoar os comportamentos do aluno como emissor e recebedor de mensagens, através da utilização e compreensão de códigos diversos - verbais e não verbais" (2004, p. 169).

No final da década de 1970, alguns esforços foram empreendidos procurando contrapor o ensino realizado nas escolas com ênfase na técnica da linguagem. Um deles foi a proposta da Secretaria de Estado da Educação de São Paulo, por meio da CENP (Coordenadoria de Estudos e Normas Pedagógicas), em conjunto com professores das Universidades Estaduais do Estado de São Paulo, coordenado pelo professor Ataliba de Castilho. Foi o processo de revisão dos Guias Curriculares Nacionais (o "verdão") com uma Proposta Curricular para o ensino de língua portuguesa $-1^{\circ}$ grau e $2^{\circ}$ graus (CENP/ SP, 1988), baseada nos estudos linguísticos da Sociolinguística, Pragmática, Semântica, Interacionismo-sociodiscursivo e nos avanços da didática ${ }^{3}$. No terceiro volume da coletânea de textos, uma discussão é apresentada sobre a "perspectiva dialógica da leitura e dos textos e a história literária" (CENP, 1988, p. 5).

O volume publica onze artigos e alguns trazem foco na teoria dialógica, outros abordam temas da literatura, textos escritos por Yara F. Vieira, Berta Waldman, Herberto Helder, Willi Bolle, Antonio Candido, Adélia Bezerra de Menezes Bolle. No artigo "Recepção ativa de textos: uma forma de diálogo", por exemplo, de Yara F. Vieira, os conceitos de "interação verbal" no contexto dialógico e "diálogo intertextual" são apresentados, e a obra Marxismo e filosofia da linguagem, de M. Bakhtin (sic) são citados em notas bibliográficas.

Como se pode notar a Proposta Curricular trouxe muitos avanços advindos das teorias linguísticas e literárias para a renovação da disciplina de Língua Portuguesa, no entanto, a realidade escolar se manteve de forma bem diferente. A expansão das faculdades particulares de Letras, com professores sem formação linguística, tornou difícil colocar em prática as várias propostas, entre elas o deslocamento da unidade de

2 MESERANI, S. Redação escolar: criatividade. São Paulo: Saraiva, 1971. SOARES, M.; CAMPOS, E.N. Técnicas de redação: as articulações linguísticas como técnica de pensamento. Rio de Janeiro: Ao Livro Técnico, 1978. ANDRÉ, H. Curso de Redação. São Paulo: Marco Editorial, 1978. BRAIT, B; NEGRINI, J. L. C.; LOURENÇO, N.R.P. Aulas de redação. São Paulo: Atual, 1980.

3 A Proposta curricular de língua portuguesa e técnicas de redação para o $2^{\circ}$ grau (CENP/ SE, 1978) foi elaborada pela primeira vez em 1978, sob a coordenação dos linguistas Ataliba de Castilho, Rodolfo Ilari, Yara Frateschi Vieira e Rita de Cássia Araújo Cêntola. 
ensino para o texto e para a produção da leitura e da escrita. Quanto aos livros didáticos de português analisados desse período, Perez discute as muitas incoerências teóricas que permaneceram frente à mudança implantada:

[...] o livro didático constitui-se em mais uma peça, pela qual a sociedade capitalista procura engendrar uma visão harmônica integrada do mundo. [...] Além do trabalho com palavras isoladas, textos isolados, aparecem as seguintes oposições: língua/fala, sociedade/indivíduo, língua/literatura, emoção/razão, realidade/literatura, poder criativo/poder racional, denotação/conotação. Dessas elaborações, é fácil chegar a formas de percepção de mundo mais camufladas: certo/errado, culto/inculto, bem/mal (PEREZ, 1991, p. 90).

Se no final da década de 1970 a redação de vestibular tinha entrado na escola por decreto federal, no início dos anos 1980 ela ganhou espaço entre pesquisadores nas universidades que se detiveram no tema da redação escolar como Rocco (1981), Pécora (1983), Franchi (1984), Geraldi (1984), entre outros. As aulas de português estiveram mergulhadas num contexto social e ideológico de redemocratização do país, embora muito desacreditado, e as novas teorias linguísticas entraram no ensino de língua materna mudando a concepção de língua e linguagem.

\section{Novas teorias em aulas de português: entre a tradição e a ruptura}

No início da década de 1980, com a abertura política brasileira, depois do longo período de ditadura militar, muitos estudos sobre linguagem, língua, texto, argumentação se intensificam. Entre eles, está a obra Problemas de redação (1983), de Pécora que analisou redações do vestibular da Unicamp. Entre os vários problemas apontados, ele identificou uma contradição nas condições de ensino-aprendizagem, uma vez que os textos eram escritos para ninguém ler e a correção em caneta vermelha marcava os erros ortográficos, de modo que o autor concluiu: "o efetivo domínio da escrita apenas pode se dar como um desdobramento da práxis linguística e jamais como uma mera assimilação de técnicas e padrões" (2011, p. 107).

O objeto de ensino, a dissertação no vestibular, entrou nas aulas de português, mas manteve as características de estudar técnicas de redação, sem confrontar diferentes pontos de vista e prática do ensino mantém-se em domínios isolados de estruturas do parágrafo. As aulas de português dessa década mantiveram um ensino de produção escrita focado no modo de escrever do autor do texto analisado, sem considerar os processos de construção do texto e de interação. Compreende-se, desse modo, a dissertação de modo limitado, como assinala Koch "apenas, a exposição de ideias alheias, sem nenhum posicionamento pessoal [...] no entanto, "a simples seleção das opiniões a serem reproduzidas já implica, por si mesma, uma opção argumentativa” (1987, p.19-20).

Em 1984, a publicação $O$ texto na sala de aula: leitura \& produção, de João Wanderley Geraldi, trouxe uma nova proposta para as aulas de português, colocando o texto como unidade principal da aula de português. Vários artigos desse livro associam a redação escolar a um não-texto, mostrando que a escola torna a escrita dos alunos desprovida de interação e com uma circulação restrita à aula. Nos artigos de Possenti (Gramática e política) e Faraco (As sete pragas do ensino de português), por exemplo, as propostas vão na direção de respeitar o processo do aluno para o ato de escrever. Geraldi acrescenta que "a construção de um texto se dá por operações discursivas com as quais [...] o locutor faz uma 'proposta de compreensão' a seu interlocutor” (1991, p.194). 
O autor identifica entre as formulações textuais os operadores de argumentação que envolvem tanto o trabalho dos sujeitos no que tange às expressões linguísticas utilizadas quanto aos sistemas de referências postos em funcionamento junto a essas expressões. (1991, p. 197)

As aulas de redação, no entanto, permaneceram no seu mundo, exigindo dos alunos uma escrita de dissertações para defenderem o ponto de vista de um outro desconhecido, redigindo ideias que não lhes pertencia.

Dez anos mais tarde, na década de 1990, a Lei de Diretrizes e Bases da Educação Nacional (LDB) foi sancionada em 1996 no governo de Fernando Henrique Cardoso com o objetivo de melhorar a qualidade da educação e enfrentar os desafios do mundo tecnológico. Um importante aspecto dessa lei foi a inclusão do ensino médio como etapa final da educação básica (Lei 9.394/96 Art. 36). Em 1998, foram implantados os Parâmetros Curriculares Nacionais de Língua Portuguesa (PCNs/Brasil, SEF, 1998) com profunda renovação advindas da teoria dos gêneros textuais (Bernard Schneuwly e Joaquim Dolz; Jean-Paul Bronckart) e dos gêneros do discurso (Mikhail Bakhtin, Valentin Volóchinov). A proposta do documento foi a integração do ensino com foco quatro eixos: leitura, produção escrita, análise linguística e oralidade.

Decorrente dessa matriz, três documentos oficiais para o ensino médio foram publicados entre 1999 e 2006. Parâmetros Curriculares Nacionais do Ensino Médio (PCNEM, 1999) que incluiu Língua portuguesa na área de Linguagens, códigos e suas tecnologias; Orientações educacionais complementares aos Parâmetros Curriculares Nacionais (PC$\mathrm{N}+\mathrm{EM}, 2002)$ e Orientações curriculares para o ensino médio: linguagens, códigos e suas tecnologias (OCEM, 2006), que trouxe uma seção específica "Conhecimentos de língua portuguesa", em que aparecem os conceitos de "texto", "linguagem" e "gêneros discursivos", calcados em Estética da criação verbal e Marxismo e filosofia da linguagem, obras de Bakhtin e o Círculo, citadas nas referências bibliográficas do documento.

Os conceitos das diferentes teorias linguísticas nortearam esses documentos oficiais, no entanto, os conceitos chegaram lentamente às aulas de português, uma vez que não houve alterações profundas nos hábitos dos professores de Língua Portuguesa. O linguista Rodolfo Ilari constata:

[...] Muito pouco dessa reforma se realizou. O professor secundário continua investindo a maior parte de seus esforços no ensino da terminologia gramatical; continua enorme o espaço reservado aos exercícios escritos; a escola continua ignorando as variedades regionais e sociais não-standard; aprofundando desse modo os preconceitos existentes; os usos da língua na escola continuam em grande medida artificiais, como se o aprendizado fosse para a escola, não para a vida (ILARI, 1997, p. 103).

Muitos professores, conscientes de que seus alunos não sabem escrever textos dissertativos, procuram nos manuais didáticos métodos para ensinar esse tipo de texto. Nesse contexto sócio-político cultural, duas questões são colocadas: Como as atividades didáticas da dissertação são propostas nos livros didáticos? Que contribuições o ensino da dissertação /argumentação oferece aos alunos do ensino médio?

Ao analisar e comparar dois manuais didáticos produzidos em duas décadas 1980 e 2000, recuperamos as atividades em torno da dissertação. Os livros selecionados foram amplamente usados nas aulas de redação: dos anos 1980, a escolha é Redação escolar: criatividade (1989), $2^{\circ}$ grau, de S. Meserani, e dos anos 2000, Texto e interação: uma 
proposta de produção textual a partir de gêneros e projetos (2000), de W. R. Cereja; T. C. Magalhães, manuais publicados pela Atual Editora.

$\mathrm{O}$ interesse por essas duas décadas se deve sobretudo pelas renovações didáticas ocorridas no período, quando teve início uma reconfiguração do ensino da dissertação, passando a se articular com a argumentação. A aproximação está relacionada aos exames vestibulares e, depois ao Exame Nacional do Ensino Médio - Enem, de modo que a força dos concursos oficiais também é um importante elemento modificador do livro didático.

A argumentação na perspectiva dialógica do discurso considera que há sujeitos que se manifestam frente a um assunto, assumindo um ponto de vista e se comprometendo com a realidade na qual estão inseridos. Bakhtin e Volóchinov tratam da interação discursiva, base do discurso argumentativo:

[...] o enunciado se forma entre dois indivíduos socialmente organizados, e, na ausência de um interlocutor real, ele é ocupado, por assim dizer, pela imagem do representante médio daquele grupo social ao qual o falante pertence. A palavra é orientada para o interlocutor, ou seja, é orientada para quem é esse interlocutor [...] Toda palavra serve de expressão ao “um” em relação ao “outro". (VOLÓCHINOV, 2017, p. 204-205).

Nessa abordagem discursiva, a produção de um texto argumentativo exige a escolha de um gênero discursivo, o que considera as esferas de circulação, de produção e de recepção do texto. Plantin esclarece que "nessa concepção, a atividade argumentativa do locutor consiste essencialmente em reformulações, adaptações, atualizações de discursos já ditos. Estamos longe da "invenção"” (2008, p. 20).

\section{Relação entre dissertação e criatividade}

Redação escolar: criatividade, escrita por Samir Curi Meserani (1936-1999), professor da PUC-SP, foi uma publicação inovadora na década de 1980. No título, a palavra "criatividade" marca a sua coleção, inscrevendo-a na Teoria da Comunicação, uma fundamentação teórica que vigorou nas décadas de 1970-80. Di Pietri explica o conceito: "a criatividade é compreendida em sua relação com o aprendizado do uso da linguagem, que implica apropriar-se da cultura e produzir significados que sejam apropriados à cultura" (2010, p. 79). Meserani esclarece o significado de texto criativo: "o que torna um texto mais criativo que outro é sua taxa de originalidade, de diferença em relação a outros" (1989, p. s/p.).

O binômio redação/criatividade tem seus fundamentos teóricos nos estudos americanos em torno de criatividade, e o autor organiza seu método em três fases: a) fluência e desinibição do ato de escrever, b) estímulo para escrever, c) criação - organização do texto, apresentando curtas instruções sobre a comunicação ou leitura dos textos em cada etapa e os critérios de avaliação.

Já nas páginas do prefácio, o autor define o tom da obra, esclarecendo seu método e orientando o uso do manual na aula de redação:

[...] tem por objeto a redação criativa, quer em gêneros livres, quer na descrição, na narração e sobretudo na dissertação. É um livro único para as três séries do $2^{\circ}$ grau, permitindo ao professor dividi-lo de acordo com o potencial de cada turma de alunos ou simplesmente seguir-lhe a sequência das trinta unidades. [...] para cumprir todas as fases do método, a aula tem que ser dobrada, de 100 minutos. [...] não é aconselhável ao professor levar as redações para casa, para "corrigir", a não ser eventualmente. (1989, s/p.). 


\section{Conexão Letras}

O volume está organizado em 30 unidades, sendo que nas primeiras quatorze destacam-se a produção de poemas, crônica, descrição, conto, narração, fotografia. Nas dezesseis unidades seguintes, o foco é a dissertação. A sequência didática enfatiza a ideia de que o indivíduo possa criar suas ideias, lendo textos que o estimulem a partir de uma afirmação inicial:

\begin{tabular}{|c|c|}
\hline Unidade 15 & $\begin{array}{l}\text { Fluência: o pensamento mítico } \\
\text { Estímulo: poema "Eros e Psique", Fernando Pessoa } \\
\text { Criação: dissertação } \\
\text { Revisão textual: O pensamento mítico }\end{array}$ \\
\hline Unidade 16 & $\begin{array}{l}\text { Fluência: o pensamento religioso } \\
\text { Estímulo: prosa mística “A prece", Gibran Kalil Gibran } \\
\text { Criação: dissertação } \\
\text { Revisão textual: O pensamento mítico }\end{array}$ \\
\hline Unidade 17 & $\begin{array}{l}\text { Fluência: o senso comum } \\
\text { Estímulo: crônica "O povo", Luís Fernando Veríssimo } \\
\text { Criação: dissertação } \\
\text { Revisão textual: O senso comum }\end{array}$ \\
\hline Unidade 18 & $\begin{array}{l}\text { Fluência: o bom senso } \\
\text { Estímulo: mapa, “Rios marcados para morrer” } \\
\text { Criação: dissertação } \\
\text { Revisão textual: O bom senso }\end{array}$ \\
\hline Unidade 19 & $\begin{array}{l}\text { Fluência: o pensamento crítico } \\
\text { Estímulo: ensaio "A conquista da felicidade", Bertrand Russel } \\
\text { Criação: dissertação } \\
\text { Revisão textual: O pensamento crítico }\end{array}$ \\
\hline Unidade 20 & $\begin{array}{l}\text { Fluência: o pensamento filosófico } \\
\text { Estímulo: ensaio "Filosofia e reflexão", Denis Huisman e André Vergez } \\
\text { Criação: dissertação } \\
\text { Revisão textual: O pensamento filosófico }\end{array}$ \\
\hline Unidade 21 & $\begin{array}{l}\text { Fluência: O pensamento científico } \\
\text { Estímulo: notícia de jornal "Astrônomos vêem explosão de uma estrela a olho } \\
\text { nu”, Folha da Tarde } \\
\text { Criação: dissertação } \\
\text { Revisão textual: O pensamento científico }\end{array}$ \\
\hline Unidade 22 & $\begin{array}{l}\text { Fluência: ciência e técnica } \\
\text { Estímulo: notícia de jornal "Nobel acha que máquina está viva", Flávio de } \\
\text { Carvalho } \\
\text { Criação: dissertação } \\
\text { Revisão textual: Ciência e técnica }\end{array}$ \\
\hline Unidade 23 & $\begin{array}{l}\text { Fluência: lógica } \\
\text { Estímulo: poemas “Se”, Rudyard Kipling, e "Kipling revisitado", José Paulo } \\
\text { Paes } \\
\text { Criação: dissertação } \\
\text { Revisão textual: A dissertação e a lógica (I) }\end{array}$ \\
\hline Unidade 24 & $\begin{array}{l}\text { Fluência: Lógica } \\
\text { Estímulo: texto científico "Dever de participação política”, Dalmo de Abreu } \\
\text { Dallari } \\
\text { Criação: dissertação } \\
\text { Revisão textual: A dissertação e a lógica (II) }\end{array}$ \\
\hline
\end{tabular}




\begin{tabular}{|l|l|}
\hline Unidade 25 & Fluência: o emissor \\
Estímulo: o texto científico "Introdução à psicologia do ser", Abraham H. \\
Maslow \\
Criação: dissertação \\
Revisão textual: A dissertação e a função emotiva
\end{tabular}

Fonte: MESERANI, 1989, 115-120.

A dissertação é abordada a partir do pensamento mítico, religioso, senso comum, bom senso, pensamento crítico, filosófico, científico, lógico e as funções da linguagem. Nas seis últimas unidades, particularmente, o autor desenvolve como eixo temático as funções da linguagem, componente da Teoria da Comunicação do linguista russo Roman Jakobson, um dos estudiosos que mais influenciou o ensino de língua portuguesa. Sua teoria procura compreender o processo da comunicação humana e toma como base a relação entre emissor e destinatário.

Para esta análise, foi escolhida a unidade 21 que trata a dissertação no pensamento científico. Na seção "Fluência e desinibição do ato de escrever: o pensamento científico, em papel branco, Meserani apresenta duas questões relacionadas à observação e a experimentação para ser discutida em grupo: "A astronomia é uma ciência que estuda os astros por meio do método da observação" e Experiência é tudo o que vivemos, tudo o que acontece em nossa vida". O componente principal da dissertação é sensibilizar o leitor a se envolver com o assunto. O tema amplo foca inicialmente na escrita de parágrafos, uma vez que há sete linhas disponíveis para respostas. $\mathrm{O}$ encaminhamento da dissertação é a exposição de ideias sobre um tema, sem se importar como ele será escrito. Explora que o interlocutor é o colega e não o professor, o que garante a ausência de correções. O autor sistematicamente insiste na presença de leitores/colegas, marcando a situação da comunicação. 
A segunda seção "Estímulo para escrever", impressa em página azul, apresenta uma notícia retirada da Folha de S. Paulo (26/02/1987), intitulada "Astronomos vêem explosão de uma estrela a olho nu". A atividade seguinte é intitulada "Criação de um texto: dissertação" e está impressa em página amarela, com espaço para os alunos escreverem livremente. A proposta predominante é para o aluno soltar as ideias de modo criativo sem considerar os movimentos argumentativos ou mesmo se preocupar com as normas gramaticais; o interesse é que o aluno se imagine um cientista muito criativo.

A página seguinte propõe uma revisão gramatical e textual, considerando se a dissertação trata do tema proposto e se há problemas de coesão como excesso de repetição (1989, p. 125). Para tanto, é necessário que o aluno conheça o assunto, saiba escrever o texto e expor sua posição. Na última seção "Revisão textual. O pensamento científico", um curto texto do autor é apresentado sobre o tema com as diferentes explicações da ciência" (1989, p. 126). A revisão gramatical trata sobre o uso da vírgula, tópico que não esclarece como o aluno pode explorar as estratégias argumentativas.

Várias unidades do volume apresentam poema ou notícia de jornal como estímulo para a produção de dissertação na primeira seção. Os temas propostos levam a uma dimensão criativa e comunicativa, entretanto longe das discussões de elaboração linguístico-discursiva de um texto dissertativo. As atividades propostas passam longe de solucionar os problemas da escrita dos alunos. O método de criatividade no ensino escolar não enfrenta os aspectos argumentativos e a tensão argumentativa do ponto de vista. Mesmo preocupado com a produção dos alunos, o foco da atividade recai no processo e numa concepção reducionista da língua que exclui o sujeito que fala, o contexto e os conflitos. Desaparece o modelo da dissertação de introdução, desenvolvimento e conclusão, submetido às normas do antigo modelo do tipo de exto, mas nenhuma orientação para coesão argumentativa é introduzida nem mesmo o foco recai para o objetivo do texto dissertativo de convencer o interlocutor de um ponto de vista. $\mathrm{O}$ método de criatividade acaba relacionado a modo intuitivo de escrever, levando a uma banalização das questões de texto, língua e linguagem.

\section{Relação entre o texto dissertativo e o argumentativo}

O início dos anos 2000 marca um momento importante para o livro didático. A publicação Texto e interação: uma proposta de produção textual a partir de gêneros e projetos, de Cereja e Magalhães, chega com profundas modificações no ensino da dissertação. Os autores já estavam há 30 anos no mercado editorial e os autores dedicam-se a compreender a elaboração do livro didático. O texto de apresentação é dirigido aos estudantes e marca como um dos objetivos o trabalho com o texto argumentativo. O título expõe as bases teóricas que fundamental a obra: texto, interação, gêneros, levando em consideração a construção dos papéis enunciativos nas diferentes esferas sociais.

O livro está organizado em doze unidades e cada uma delas inclui capítulos, totalizando 36 capítulos. Na unidade 12 "Argumentar para persuadir", última seção do livro, está composta de cinco capítulos, como mostra o quadro a seguir:

\begin{tabular}{|l|l|}
\hline \multicolumn{2}{|c|}{ UNIDADE 12 - ARGUMENTAR PARA PERSUADIR } \\
\hline \multicolumn{2}{|c|}{ Gêneros trabalhados } \\
\hline Capítulo 32 & O texto dissertativo-argumentativo \\
\hline Capítulo 33 & O texto dissertativo-argumentativo: o parágrafo \\
\hline Capítulo 34 & O texto dissertativo-argumentativo: a informatividade e o senso comum \\
\hline
\end{tabular}




\begin{tabular}{|l|l|}
\hline Capítulo 35 & O texto dissertativo-argumentativo: formas de desenvolvimento de suas partes \\
\hline Capitulo 36 & O texto dissetativo-argumentavo poetico
\end{tabular}

O capítulo é apresentado em nove páginas com foco na análise da proposta de redação da Fuvest e da dissertação bem avaliada pela banca examinadora.

$\mathrm{Na}$ abertura dessa unidade intitulada "O texto dissertativo-argumentativo", está expresso o objetivo de analisar a proposta de dissertação do exame vestibular da Fuvest de 1999. Nas primeiras linhas, os autores explicam o que é a produção de dissertação:

[...] dada a natureza quase sempre polêmica dos temas, o que se espera, na verdade, é que o aluno produza um texto que seja capaz de analisar determinado problema da realidade sob vários ângulos e, ao mesmo tempo, argumentar em defesa de seu ponto de vista. Em suma, espera-se que ele produza um texto dissertativo-argumentativo. (CEREJA; MAGALHÃES, 2000, p. 302)

A possibilidade de rebatizar dissertação como um texto dissertativo-argumentativo marca uma ruptura com o modelo tradicional sob vários pontos fundamentais. No plano da forma composicional, as seções são designadas, considerando a dissertação do vestibular um gênero textual: "Explorando o gênero", "Produzindo o texto dissertativo-argumentativo", "A técnica da contra-argumentação - você acha que o jovem de hoje é mais individualista do que o de outras gerações? Sim x não", "Exercício", "Produzindo o texto dissertativo-argumentativo", "Debatendo", "Produzindo o texto" (Fuvest/SP adaptado).

$\mathrm{Na}$ sequência didática proposta, há um predomínio da força da tradição escolar mantendo ainda referências com as partes do texto dissertativo: "introdução, desenvolvimento, conclusão". Termos do texto argumentativo como a "progressão textual", "estratégias de construção" e "retomada de referentes", "estratégias de progressão textual" e as "esferas de circulação e recepção" ainda são mantidas distantes dos estudantes e o material insiste na forma da dissertação e pouco ou quase nada na discussão da formação de um ponto de vista e no conteúdo.

\section{Considerações finais}

O ensino da dissertação, dessa maneira, enquanto gênero argumentativo entra no livro didático, mas não sem dificuldade, uma vez que os dois planos, enunciativo e discursivo da argumentação aguardam para serem desenvolvidos. Cabe lembrar que na década de 1990 a revista francesa Pratiques, coordenada pelo professor André Petitjean publicou números específicos sobre o assunto Dissertation, Argumentation e artigos como, por exemplo, de Isabelle Delcambre (1992), Delforce (1992), Michel Charolles (1992), Françoise Collinet (2014), entre muitos outros, assim como alguns artigos de Alan Rabatel que discutem o tema da argumentação e ensino. Recentemente, o Dictionnaire de l'argumentation: une introduction aux études d'argumentation, de Christian Plantin (2016) desenvolve amplamente o tema da argumentação.

A força da tradição escolar no ensino da dissertação ainda se impõe nos livros didáticos analisados do início do século XXI. E o texto dissertativo-argumentativo se apresenta como um gênero textual, mas tratado de modo indireto, continua tendo um único interlocutor: o professor ou o avaliador do vestibular. A ausência de vida verdadeira no texto dissertativo-argumentativo produzido pelo aluno acaba por remeter de novo a aspectos composicionais do gênero, deixando de considerar que o texto é escrito em um tempo e 


\section{Conexão Letras}

espaço real e que o autor está ligado a uma esfera ideológica. No entanto, os alunos, continuam tendo propostas para escrever temas sem saber porquê escrevem, nem para quem escrevem; enfim, sem nenhum entusiasmo, a dissertação torna-se um exercício difícil de ser cumprido pelos estudantes que almejam uma vaga na universidade.

\section{Referências}

ANDRÉ, H. Curso de Redação. São Paulo: Marco Editorial, 1978.

BAKHTIN, M. Teoria do romance I: a estilística. São Paulo: Editora 34, 2015.

Tradução, prefácio, notas e glossário de Paulo Bezerra (Org.), edição russa de Serguei Botcharov; Vadim Kójinov.

BRAIT, B; NEGRINI, J. L. C.; LOURENÇO, N. R. P. Aulas de redação. São Paulo: Atual, 1980.

BRASIL. Ministério da Educação. Orientações curriculares para o ensino médio: linguagens, códigos e suas tecnologias. Brasília: MEC, 2006, p. 17-46.

. Ministério da Educação e do Desporto. Parâmetros Curriculares Nacionais Língua Portuguesa - $3^{\circ}$ e $4^{\circ}$ ciclos. Brasília: MEC, 1998.

BUNZEN, C. Da era da composição à era dos gêneros: o ensino de produção de texto no ensino médio. In: BUNZEN, C.; MENDONÇA, M. (Org.). Português no ensino médio e formação do professor. São Paulo: Parábola Editorial, 2006, p.139-161.

. Livro didático de língua portuguesa: um gênero do discurso. (Dissertação de mestrado). Campinas: IEL/UNICAMP, 2005.

CEREJA, W.; MAGALHÃES, T. C. Texto e interação: uma proposta de produção textual a partir de gêneros e projetos. São Paulo: Atual, 2000.

CHAROLLES, M. La dissertation quand même. Pratiques. La dissertation. Metz: Cresef, n. 68, 1990, p. 5-16.

DELCAMBRE, I. De l'argumentation à la dissertation. Analyse d'une démarche d'apprentissage. Pratiques. La dissertation. Metz: Cresef, n. 68, 1990, p. 17-43.

DIONISIO, A. P.; BEZERRA, M. A. (Org.). O livro de português: múltiplos olhares. 2. ed. Rio de Janeiro: Lucerna, 2003.

DI PIETRI, E. Sobre a constituição da disciplina curricular de língua portuguesa.

Revista Brasileira de Educação, v. 15, n. 43, 2010, p. 70-197.

FRANCHI, E. P. E as crianças eram difíceis: a redação na escola. São Paulo: Martins

Fontes, 1984.

GERALDI, J. W. (Org.). O texto em sala de aula: leitura \& produção. Cascavel:

Assoeste, 1984.

. Portos de passagem. São Paulo: Martins Fontes, 1991.

KOCH, I. G. V. Argumentação e linguagem. São Paulo: Cortez, 1987.

MESERANI, S. Redação escolar: criatividade. São Paulo: Saraiva, 1971.

PARISI, L. M. P. Livro didático de português: entre as concepções de ensino, os trilhos da lei e as sendas do texto. (Tese de doutorado). USP, 2004.

PÉCORA, Á. Problemas de redação. São Paulo: Martins Fontes, 1983.

PEREZ, J. R. R. Lições de português: tradição e modernidade no livro escolar.

Campinas: Editora da Unicamp, 1991.

PLANTIN, C. Argumentação biface. In. LARA, G.; MACHADO, I.L.; EMEDIATO, W. Análises do discurso hoje. Rio de Janeiro: Nova Fronteira, v. 2, 2008, p. 13-26. 
. Dictionnaire de l'argumentation. Une introduction aux études argumentatives.

Lyon: ENS Éditions, 2016.

RABATEL, A. Retour sur un parcours en énonciation. In: CARCASSONNE, M.;

CUNHA, D. A.; DONAHUE, C.; FRANÇOIS, F. Points de vue sur le point de vue. Un essai de réflexion collective. Limoges: Lambert-Lucas, 2015, p. 327-355.

ROCCO, M. T. F. Crise na linguagem: a redação no vestibular. São Paulo: Mestre Jou, 1981.

ROJO, R. Gêneros de discurso/texto como objeto de ensino de línguas: um retorno ao trivium? In. SIGNORINI, I. (Org.) [Re] discutir texto, gênero e discurso. São Paulo: Parábola, 2008, p. 73-101.

SÃO PAULO. Secretaria da Educação. CENP. Subsídios à proposta curricular de língua portuguesa para o $1^{\circ}$ e $2^{\circ}$ graus. Coletânea de textos. v. III. São Paulo: SE/ CENP, 1988.

SOARES, M.; CAMPOS, E.N. Técnicas de redação: as articulações linguísticas como técnica de pensamento. Rio de Janeiro: Ao Livro Técnico, 1978.

VOLÓCHINOV, V. (Círculo de Bakhtin). Marxismo e filosofia da linguagem: problemas fundamentais do método sociológico na ciência da linguagem. São Paulo: Editora 34, 2017, Tradução, notas e glossário Sheila Grillo; Ekaterina Vólkova Américo. Ensaio introdutório Sheila Grillo.

Recebido em: 27/04/2018 Aceito em: 18/05/2018 